\title{
DEKSMEDETOMIDINO NAUDOJIMAS NEOPERACINĖJE APLINKOJE
}

\author{
Lina Šimonytė ${ }^{2}$, Ilona Razlevičè $\dot{1}^{1}$, Laura Lukošienè $\dot{1}^{1}$, Andrius Macas ${ }^{1}$ \\ ${ }^{1}$ Lietuvos sveikatos mokslu universiteto Medicinos akademijos Anesteziologijos klinika, \\ ${ }^{2}$ Lietuvos sveikatos mokslu universiteto Medicinos fakultetas
}

Raktažodžiai: deksmedetomidinas, anestezija, sedacija, už operacinès ribų.

\begin{abstract}
Santrauka
Lietuvoje daugejant endoskopinių ir radiologinių tyrimų, didèja sedacijos poreikis. Šioms procedūroms reikalingas saugus, patogus naudoti ir kuo mažiau nepageidaujamo poveikio keliantis medikamentas. Vis svarbesnę vietą šiuolaikinèje sedacijoje užima $\alpha 2$ adrenoreceptorių agonistas deksmedetomidinas, dar naujas anesteziologo praktikoje, jau patvirtintas naudoti operacijų metu intensyviosios terapijos skyriuose bei vaikų ir suaugusiųjų sedacijai invazinių ir neinvazinių procedūrų metu. Šio darbo tikslas - apžvelgti naujausius mokslinius tyrimus, susijusius su deksmedetomidino vartojimu ir nustatyti jo vartojimo galimybes neoperacinejje aplinkoje. Kokybinei turinio analizei atrinkta 18 straipsnių iš PubMed, Cochrane, UpToDate, Medline duomenų bazių. Analizès rezultatai parodé, kad būdamas selektyvesnis už klonidiną, šis vaistas sukelia sedaciją, analgeziją ir anksiolizę, bet nesukelia kvėpavimo centro slopinimo ar ypač nepalankių kardiovaskulinių ịvykių, todèl gali būti naudojamas ne tik operacinèse ir intensyviosios terapijos skyriuose, bet ir atliekant endoskopines procedūras, radiologinius ir kitus diagnostikos tyrimus.
\end{abstract}

\section{Ivadas}

Gydytojo anesteziologo praktikoje sedacija ir anestezija neoperacineje tapo kasdienybe. Didejant radiologiniu bei kitų tyrimų paklausai ir prieinamumui, atsirado poreikis jų dali atlikti taikant sedaciją [1]. Radiologinių ar endoskopinių tyrimų metu vaikams ir suaugusiesiems, sergantiems klaustrofobija ir kitomis, tyrimo kokybès negalinčiomis užtikrinti, ligomis, sedacija yra būtina, siekiant tinkamai atlikti tyrimą ir pasiekti reikiamų rezultatų. Tokioms procedūroms atlikti reikalingi medikamentai, kurių veikimo pradžia greita, sau- gūs ir patogūs vartoti, sukelia trumpalaikę sedaciją, nedidelè šalutinio poveikio tikimybè [2].

Deksmedetomidinas - tai sąlyginai naujas medikamentas gydytojo anesteziologo praktikoje, ypač selektyvus $\alpha 2$ adrenoreceptorių agonistas [3]. Šis vaistas yra apytiksliai 8-10 kartų selektyvesnis už klonidiną, pasižymintį ilgesniu veikimu, todèl patogus vartoti, siekiant išvengti nepageidaujamo poveikio ir norint greito sedacijos nutraukimo [4]. Literatūros duomenimis, deksmedetomidinas yra efektyvus ir saugus medikamentas, tinkamas naudoti intensyviosios terapijos skyriuose, operacinėse bei pacientų sedacijai procedūru ar tyrimų metu. Šis vaistas gali būti naudojamas atliekant kolonoskopijas, transezofagines echokardiografijas, litotripsijas [3]. Vaikams deksmedetomidinas tinkamas diagnostiniu tyrimų neoperacinejje aplinkoje metu [5].

Darbo tikslas - atlikti sisteminę literatūros šaltinių duomenų analizę, siekiant išsiaiškinti deksmedetomidino vartojimo galimybes, riziką, naudą ir žalą neoperacinejje ar intensyviosios terapijos skyrių aplinkoje.

\section{Darbo objektas ir metodai}

Literatūros paieška atlikta mokslinèse elektroninèse PubMed, Cochrane, UpToDate, Medline duomenų bazėse. Duomenų analizei pasirinkti straipsniai nuo 2006 iki 2019 metų. Iš viso atrinkta 18 straipsnių, atlikta jų teksto analizè. Šiame straipsnyje pateikiami apibendrinti sisteminès jų analizès rezultatai.

Deksmedetomidino veikimas. Deksmedetomidinas veikia su $\mathrm{G}$ baltymu susijusius $\alpha 2$ adrenerginius receptorius, kurių yra 3 potipiai $(\alpha 2 \mathrm{~A}, \alpha 2 \mathrm{~B}, \alpha 2 \mathrm{C})$. Visi jie išsidèstę centrinejje, periferinejje bei autonominejje nervų sistemose, vidaus organuose ir kraujagyslèse. Deksmedetomidinas turi didesnį afinitetą $\alpha 2 \mathrm{~A}-\mathrm{AR}$ ir $\alpha 2 \mathrm{C}$-AR nei klonidinas. Deksmedetomidinas sukelia sedaciją, analgeziją, anksiolizę, tačiau nesukelia kvėpavimo centro slopinimo. Pagrindinis šio vaisto veikimas pasireiškia $\alpha 2 \mathrm{~A}$ adrenoreceptoriams, esantiems mèlynojoje dèmeje (sedacinis po- 
veikis) ir nugaros smegenyse (analgezinis poveikis) [3,4].

Farmakokinetika. Vartojamas ị veną deksmedetomidinas pasiskirsto greitai, 94 proc. jungiasi su baltymais. Per burną vartojamo deksmedetomidino bioprieinamumas yra žemas dèl greito metabolizmo, tačiau per nosị ir po liežuviu biologinis prieinamumas siekia 84 proc., todèl jis patogus vartoti vaikams premedikacijos tikslais. Deksmedetomidino pasiskirstymo pusperiodis yra 6 minutès, o eliminacijos -2 valandos [6]. Deksmedetomidinas metabolizuojamas kepenyse per gliukuronidazès ir citochromo P450 sistemas. Jeigu sutrikusi inkstų ar kepenų funkcija, metabolizmas ir klirensas gali būti sulèteję. Didžioji dalis šio medikamento $(>90 \%)$ išsiskiria nepakitusi su šlapimu ir tik maža dalis su išmatomis $[3,4]$.

Klinikinis poveikis. Deksmedetomidinui veikiant širdyje esančius receptorius, didejja bradikardijos tikimybè (pasireiškia vagomimetinis poveikis), o periferinèse kraujagyslèse esančius receptorius - hipotenzijos tikimybè dèl sukeliamos vazodilatacijos, tačiau prieš ši poveikị deksmedetomidinas gali sukelti laikiną hiperteziją. Tai aiškinama deksmedetomidino poveikiu pirmiausiai $\alpha 2 \mathrm{~B}$ adrenoreceptoriams, todèl gali būti stebima trumpalaikè hipertenzija, o vèliau, veikiant $\alpha 2 \mathrm{~A}$ adrenoreceptorius, gali vystytis hipotenzija [3]. Atliktų tyrimų duomenimis, net vartojant dideles deksmedetomidino dozes, kvépavimo centro slopinimo nebuvo. Trachejjos intubacijos metu deksmedetomidinas padeda išvengti galimos hipertenzijos ir tachikardijos [7]. Veikdamas centrinę nervų sistemą, deksmedetomidinas mažina smegenų kraujotaką bei deguonies poreikị, taip pat buvo pastebèta geresnè išeminio ar trauminio galvos smegenų pažeidimo gydymo baigtis [3]. Drebulys galimai slopinamas veikiant $\alpha 2 \mathrm{~B}$ adrenoreceptorius, esančius skersaruožiuose raumenyse, o diurezė skatinama slopinant renino išsiskyrimą bei didinant glomerulu filtracijos greitị. Greta šio pagrindinio poveikio, deksmedetomidinas slopina lygiujų raumenų susitraukimą bei žarnyno peristaltiką, mažina seilèteki [4]. Šio vaisto veikimas kitoks, nei benzodiazepinų, jis yra tinkamas naudoti ažituotiems, neramiems pacientams, turintiems toleranciją benzodiazepinams [8]. Atlikta nemažai metaanalizių, kuriose įrodyta, jog deksmedetomidinas nesukelia posedacinès ažitacijos, sujaudinimo, dezorienatacijos ar delyro vaikų populiacijoje [5]. Deksmedetomidinas sumažina opioidų, benzodiazepinų ir propofolio poreiki anestezijos metu [2].

Deksmedetomidinas tiekiamas deksmedetomidino hidrochlorido injekcinèmis formomis $50 \mathrm{mcg} / 0,5 \mathrm{ml}, 100 \mathrm{mcg} /$ $\mathrm{ml}$ ar $200 \mathrm{mcg} / 2 \mathrm{ml}$. Veikimas pasireiškia po 5, o maksimalus poveikis po 15 minučių [4]. Deksmedetomidinas gali būti naudojamas kaip adjuvantas centrinès ar periferinès nervu blokados metu [3]. Deksmedetomidino antagonistas atipamezolis lengvai panaikina $\alpha 2 \mathrm{~A}$ adrenoreceptorių agonistu poveikị, slopina analgezini ir sedacinị deksmedetomidino efektą. Vartojant deksmedetomidiną kartu su kitais anestetikais, sedaciniais medikamentais ar opioidais, sustiprèja šių vaistų poveikis. Reikètų atsargiai skirti su kitais neigiamą chronotropinị poveikị širdžiai ar vazodilatacinị poveikị turinčiais medikamentais $[3,4]$.

Naudojimas suaugusiems pacientams. Jungtinèse Amerikos Valstijose 98 procentai planiniu endoskopinių tyrimų atliekami taikant sedaciją [9]. Didejjant šių tyrimų skaičiui Lietuvoje, didžioji dalis tokių procedūrų atliekama taikant sedaciją, taip mažinant paciento nerimą ir baimę bei užtikrinant komfortą procedūros metu. Vis dèlto daugelis medikamentų, tokių kaip propofolis, barbitūratai ir kiti, didina intubacijos bei stacionarizavimo ị intensyviosios terapijos skyrių riziką [8]. Iprastinèmis sąlygomis sedacijai naudojamas propofolis, kuris pasižymi greitesne poveikio pradžia, lengvu titravimu bei trumpu veikimo pusperiodžiu, tačiau propofolis pasižymi ir raumenų tonuso mažinimu bei kvėpavimo centro slopinimu, galinčiu sukelti kvejpavimo takų obstrukciją [10]. İrodyta, jog tai priklauso nuo vartojamos šio medikamento dozès, tad kombinuojant ji kartu su ketaminu, deksmedetomidinu ar opioidais, nepageidaujamo poveikio pavyksta išvengti arba jị sumažinti [3]. Irodyta, jog deksmedetomidinas gali būti sẻkmingai vartojamas trumpalaikių procedūrų bei tyrimų metu, skiriant jị vieną ar kartu su propofoliu. Gastrointestinalinių endoskopijų metu ši kombinacija sutrumpina atsibudimo laiką po procedūros [10].

Deksmedetomidinas pasižymi ir šalutiniu poveikiu. Yra duomenų, jog deksmedetomidinas kartu su propofoliu gastrointestinalinių endoskopinių procedūrų metu sukelia bradikardiją ir hipotenziją dažniau, nei propofolis kartu su ketaminu ar sufentaniliu, taip pat šioms būklèms koreguoti dažniau prireikia atropino ir efedrino [9]. Tokie nepageidaujami ịvykiai dažniau pasireiškia pacientams, kurie vartoja $\beta$ agonistus, digoksiną ar yra hipovolemiški [11]. Kita sritis - radiologiniai tyrimai. Magnetinio rezonanso tomografija (toliau - MRT) ar tyrimai, kurių metu vartojami radioaktyvūs izotopai, pasižymi maža erdve, dideliu garsu, ypač MRT atlikimo metu, dèl to klaustrofobija sergantiems pacientams gali išprovokuoti panikos atakas. Pagrindinis tikslas - sumažinti paciento nerimą bei užtikrinti, jog tyrimas bus atliktas kokybiškai. Dažniausiai šiems atvejams naudojamas propofolis, deksmedetomidinas ar midazolamas, arba šių medikamentų kombinacija. Vis dèlto, palyginus propofolio ir deksmedetomidino sedaciją, pastebèta, kad skiriant pastarajị vaistą, anksiolizei pasiekti reikia ilgesnio laiko [14]. Rekomeduojama dozė vyresnio amžiaus pacientams yra $0,5 \mathrm{mcg} / \mathrm{kg}$ infuzija per $10 \mathrm{~min}$. [16]. Endoskopinèms procedūroms bei radiologiniams tyrimams rekomenduojama $1 \mathrm{mcg} / \mathrm{kg}$ ir palaikomoji $0,2 \mathrm{mcg} / \mathrm{kg}$ dozè, veikimas prasideda mažiau nei po $5 \mathrm{~min}$, 
o didžiausias poveikis pasireiškia per 15 minučių $[3,14,16]$.

Naudojimas vaikams. Dèl didelio judrumo ir baimès, vaikams taikoma sedacija, norint atlikti įvarius radiologinius tyrimus. Šis metodas pagelbeja pacientams, sergantiems autizmu ar turintiems hiperaktyvumo sutrikimą [6]. Dèl ịvairių patologijų vaikams vis dažniau atliekama magnetinio rezonanso tomografija, kuri neturi radiacijos ir yra pakankamai saugi, o taip pat daugybė kitų radiologiniu diagnostinių tyrimų $[5,12]$. Dèl ypač ilgos tyrimo trukmès, vaikai turi būti seduojami, siekiant išvengti judesio sukeltų artefaktų [12]. Idealus medikamentas vaikų sedacijai turètų minimaliai veikti kardiovaskulinę ir kvėpavimo sistemos funkcijas bei garantuoti gerą tyrimo rezultatą [6]. Tam gali būti naudojamas propofolis, kurio greita veikimo pradžia, tačiau naudojimas rizikingas dèl dažno šalutinio poveikio, tokio kaip kvèpavimo slopinimas, hipotenzija ar bradikardija [12]. Alternatyva propofoliui gali būti deksmedetomidinas [5]. Studijos rodo, kad deksmedetomidinas ir propofolis mažina delyro riziką, o kombinuojamas su midazolamu, deksmedetomidinas gali pakeisti propofolị radiologinių tyrimų metu. Atliktos metaanalizès rodo, jog deksmedetomidinas sukelia tokią pat sedaciją, kaip ir propofolis. Centruose, kur propofolio vartojimas ribojamas, ar pacientas alergiškas, deksmedetomidinas gali būti puiki alternatyva, priešingai nei propofolis, nesukelianti kvėpavimo takų kolapso, todèl tinkama naudoti neintubuotiems pacientams [6]. Šis vaistas gali būti sékmingai naudojamas vaikams, sergantiems miego apnèja [12]. Skiriant deksmedetomidiną premedikacijai, sumažeja sevoflurano poreikis bei laikas iki ekstubacijos [13]. Naudojamas vaikams radiologinių tyrimų metu, deksmedetomidinas mažina ažitacijos po sevoflurano naudojimo riziką [15]. Nepaisant gero ir reikiamo efekto, naudojant deksmedetomidiną, ilgesnis atsigavimo laikas, lyginant su propofoliu [12]. Kaip ir suaugusiems pacientams, naudojant deksmedetomidiną vaikams, gali pasireikšti laikinos hipertenzijos epizodai su vèliau stebima hipotenzija bei bradikardija, tačiau vaikų populiacijoje šios būklès dažniausiai praeina savaime ir retai prireikia medikamentinio gydymo [6]. JAV praktikoje naudojama $1 \mathrm{mcg} / \mathrm{kg}$ deksmedetomidino dozė per $10 \mathrm{~min}$, kombinuojant kartu su $0,1 \mathrm{mg} / \mathrm{kg}$ midazolamo doze, véliau skiriama $1 \mathrm{mcg} / \mathrm{kg} / \mathrm{val}$ deksmedetomidino palaikomoji dozė [5]. S. McMorrow su bendraautoriais pastebèjo, kad mažesnès deksmedetomidino dozès vaikams, iki $2 \mathrm{mcg} / \mathrm{kg}$ boliusu per $10 \mathrm{~min}$, vèliau palaikomoji $1 \mathrm{mcg} / \mathrm{kg} /$ val dozè, radiologinių tyrimų metu pasirodè nepakankamos atlikti ilgesnius tyrimus dẻl poreikio stabdyti tyrimą bei skirti papildomai midazolamo, propofolio ar didinti deksmedetomidino. Autoriai siūlo skirti didelę pradinę dozę $3 \mu \mathrm{g} / \mathrm{kg}$ per $10 \mathrm{~min}$, vèliau mažinant iki $2 \mu \mathrm{g} / \mathrm{kg}$ per valandą. Literatūroje aprašoma, kad net įvykus atsitiktiniam deksmedetomidino perdozavimui, kvėpavimas nėra slopinamas [17]. Kitame tyrime K.Mason su kolegomis ištyre 747 vaikus MRT tyrimo metu, kurie buvo seduojami didele deksmedetomidino doze ir pastebejo, kad skiriant dideles dozes, pasiekama tinkama sedacija, o įvykę kardiovaskulinès sistemos pokyčiai svyruoja 20 proc. ribose, lyginant su pradiniu dydžiu ir nesukelia neigiamų padarinių [18].

\section{Išvados}

Vis didesnę svarbą anesteziologo-reanimatologo kasdienybejje užima darbas neoperacinèje aplinkoje ar intensyviosios terapijos skyriuose. Siekiant suteikti maksimalu komfortą suaugusiems ir vaikams radiologinių ar kitų diagnostinių tyrimų metu, svarbu pasiekti tinkamą sedaciją, nesukeliant pavojaus paciento saugumui ar gyvybei. Dažniausiai naudojamas propofolis pasižymi kvėpavimo slopinimu, kuris neintubuotiems pacientams gali sukelti didelę riziką. Alternatyva propofoliui gali būti deksmedetomidinas, kuris sukelia panašią sedaciją, tačiau neslopina kvẻpavimo centro, nesukelia kvėpavimo takų kolapso, yra saugus ir patogus naudoti vaikams ir suaugusiems.

\section{Literatūra}

1. Stremaitytė V., Dobrovolskytė U., Rimaitis M., Bilskienė D. Sedacija ir anestezija neoperacinèje aplinkoje: iššūkiai ir rekomendacijos. Visuomenès sveikata, 2019;29(3): 74-78.

https://doi.org/10.5200/sm-hs.2019.040

2. Silva-Jr J, Katayama HT, Nogueira FAM, Moura TB, Alves TL, de Oliveira B,W. Comparison of dexmedetomidine and benzodiazepine for intraoperative sedation in elderly patients: a randomized clinical trial. Reg Anesth Pain Med 2019;44(3):319. https://doi.org/10.1136/rapm-2018-100120

3. Naaz S, Ozair E. Dexmedetomidine in current anaesthesia practice- a review. Journal of clinical and diagnostic research: JCDR 2014;8(10):GE01-GE4.

https://doi.org/10.7860/JCDR/2014/9624.4946

4. Kaur M, Singh PM. Current role of dexmedetomidine in clinical anesthesia and intensive care. Anesthesia, essays and researches 2011;5(2):128-33.

https://doi.org/10.4103/0259-1162.94750

5. Tang Y, Meng J, Zhang X, Li J, Zhou Q. Comparison of dexmedetomidine with propofol as sedatives for pediatric patients undergoing magnetic resonance imaging: a meta-analysis of randomized controlled trials with trial sequential analysis. Experimental and therapeutic medicine 2019;18(3):1775-1785. https://doi.org/10.3892/etm.2019.7751

6. Ahmed SS, Unland T, Slaven JE, Nitu ME. High dose dexmedetomidine: effective as a sole agent sedation for children undergoing MRI. International journal of pediatrics 2015;2015:397372.

https://doi.org/10.1155/2015/397372 
7. Zhan-Ying G, Chang-Ming W, Shuai T, Lin-Lin T, Yu-Feng H. Comparison of effects of different doses dexmedetomidine on inhibiting tracheal intubation-evoked haemodynamic response in the elderly patients. Journal of clinical and diagnostic research: JCDR 2015;9(9):UC10-UC13.

https://doi.org/10.7860/JCDR/2015/14624.6455

8. Calver L, Isbister GK. Dexmedetomidine in the emergency department: assessing safety and effectiveness in difficult-to-sedate acute behavioural disturbance. Emerg Med J 2012;29(11):915. https://doi.org/10.1136/emermed-2011-200849

9. Yin S, Hong J, Sha T, Chen Z, Guo Y, Li C, et al. Efficacy and tolerability of sufentanil, dexmedetomidine, or ketamine added to propofol-based sedation for gastrointestinal endoscopy in elderly patients: a prospective, randomized, controlled trial. Clin Ther 2019;41(9):1864-1877.e0.

https://doi.org/10.1016/j.clinthera.2019.06.011

10. Abdelgalel EF. Dexmedetomidine added to propofol for druginduced sleep endoscopy in adult patients with obstructive sleep apnea: randomized controlled trial. Egyptian Journal of Anaesthesia 2018;34(4):151-157.

https://doi.org/10.1016/j.egja.2018.09.001

11. Jones GM, Murphy CV, Gerlach AT, et al. High-dose dexmedetomidine for sedation in the intensive care unit: an evaluation of clinical efficacy and safety. Ann Pharmacother 2011;45:740e 747 .

https://doi.org/10.1345/aph.1P726

12. Fang H, Yang L, Wang X, Zhu H. Clinical efficacy of dexmedetomidine versus propofol in children undergoing magnetic resonance imaging: a meta-analysis. International journal of clinical and experimental medicine 2015;8(8):11881-11889.

13. Di M, Yang Z, Qi D, et al. Intravenous dexmedetomidine pre-medication reduces the required minimum alveolar concentration of sevoflurane for smooth tracheal extubation in anesthetized children: a randomized clinical trial. BMC Anesthesiol 2018;18(1):9.

https://doi.org/10.1186/s12871-018-0469-9

14. Loh P, Ariffin MA, Rai V, Lai L, Chan L, Ramli N. Comparing the efficacy and safety between propofol and dexmedetomidine for sedation in claustrophobic adults undergoing magnetic resonance imaging (PADAM trial). J Clin Anesth 2016;34:216-222. https://doi.org/10.1016/j.jclinane.2016.03.074

15. Isik B, Arslan M, Tunga AD, Kurtipek O. Dexmedetomidine decreases emergence agitation in pediatric patients after sevoflurane anesthesia without surgery. Pediatric Anesthesia 2006;16(7):748-753.

https://doi.org/10.1111/j.1460-9592.2006.01845.x
16. Scott-Warren VL, Sebastian J. Dexmedetomidine: its use in intensive care medicine and anaesthesia. BJA Ed 2016;16(7): 242-246.

https://doi.org/10.1093/bjaed/mkv047

17. McMorrow SP, Abramo TJ. Dexmedetomidine sedation: uses in pediatric procedural sedation outside the operating room. Pediatr Emerg Care 2012;28(3):292-296.

https://doi.org/10.1097/PEC.0b013e3182495e1b

18. Mason KP, Zurakowski D, Zgleszewski SE, Robson CD, Carrier M, Hickey PR, Dinardo JA. High dose dexmedetomidine as the sole sedative for pediatric MRI. Pediatric Anesthesia 2008;18:403-411.

https://doi.org/10.1111/j.1460-9592.2008.02468.x

\section{USAGE OF DEXMEDETOMIDINE OUTSIDE OPERATING ROOM}

\section{L. Šimonytė, I. Razlevičè, L. Lukošienė, A. Macas}

Keywords: dexmedetomidine, anesthesia, sedation, nonoperating room.

Summary

As the number of diagnostic procedures is increasing, some of them has to be performed under sedation or anesthesia. It requires a fast-acting medication, minimizing the risk of adverse effects. An example of this medication is dexmedetomidine, which, being particularly selective for $\alpha 2$-adrenoreceptor agonist, does not inhibit the respiratory center and is useful in paediatrics and adults practice.

The aim of this study is to review literature and determine pros and cons of dexmedetomidine using in nonoperating room.

Literature review performed in scientific PubMed, Cochrane, UpToDate, Medline databases from 2006 till 2019. A total of 18 articles were analyzed. This review article presents the pediatric and adult studies that have been published thus far regarding dexmedetomidine use for procedural sedation.

Analysis of dexmedetomidine using did not show any respiratory depression. The most commonly reported adverse reactions were hypotension and bradycardia, however, most children and adults experienced no adverse effects during the dexmedetomidine infusion.

Complementary medications such as midazolam or propofol are often administered to prevent unpredictable wake-up during diagnostic procedures.

Correspondence to: ilonos_pastas@yahoo.com

Gauta 2020-02-20 